\title{
Legal GuARANTEes For the Protection of Public Health Against the SpREad OF INFECTIOUS DISEASES - NEW Challenges AND THREATS
}

Accepted
27. 01. 2021
Revised
06. 03. 2021
Published
23. 04. 2021

Keywords

public

health,

infectious

diseases,

legal

safeguards for the

protection of

human

life and

health,

statistical

data,

protective

vaccinations

\section{SEBASTIAN CZECHOWICZ}

University of Lódź, Department of Criminal Law, Łódź, Poland.

E-mail: sebastianczechowicz.official@gmail.com

CORRESPONDING AUTHOR

sebastianczechowicz.official@gmail.com

Abstract Public health is considered a social value. Effective laws are critical to achieving high levels of public health. The legislature faces many challenges in protecting human life and health. The COVID-19 pandemic is the best evidence of this. Effective prevention of infectious diseases and epidemic threats should not escape the legislature's attention. Both preventive measures and effective fight against already existing threats are essential for their elimination. This work presents the results of research on the doctrine of public health and the legal guarantees of its protection. The paper presents the most recent threats to human life and health associated with the spread of infectious diseases. The paper also presents the results of statistical research on the effectiveness of the fight against the spread of infectious diseases. 


\section{$1 \quad$ Introduction}

Life and health are the most important values to humans. In the modern world, these values are protected by law. It is unimaginable that these values would not be legally protected. They are protected primarily by provisions of constitutional law and public law. Protection of human life and health can be analyzed in terms of many factors. These include epidemic threats related to the spread of infectious diseases.

Infectious diseases have posed a very serious threat to human life and health for centuries. High mortality rates have been mainly due to the lack of knowledge about many diseases and weak early detection systems. Legal guarantees for the protection of the most important values for societies - life and health - are essential elements of public health. States are unable to adequately counter such threats without enacting both effective and comprehensive provisions of universally binding law. This assertion is painfully clear during the present time of the global COVID-19 pandemic. The reasons for undertaking the research problem presented herein extend beyond the COVID-19 pandemic, however, and also include other epidemic phenomena, such as the annual flu and measles epidemics which have been recurring for many years. The existence of these phenomena may be at least partially associated with imperfect legal provisions and many years of legislative neglect in the area of protection of human health and life against the spread of infectious diseases, on both the national level and the international level.

During the current COVID-19 pandemic, it is noticeable that many ad hoc legislative initiatives have been taken both on the European Union level and in national legislation. We must realize that biological pathogens do not respect national borders and only comprehensive, anti-epidemic legislation will lead to greater efficiency and the ability of governments to act more nimbly and in a more coordinated fashion when future epidemic threats caused by the spread of various infectious diseases occur.

The concept of public health suggests a reference to another catalogue of protected goods for the general population. It is therefore necessary to start with a definition of public health, which correlatively time will demonstrate the legally of health and life as protected goods in relation to the general population. 
The idea for defining public health more broadly in the international science arena in this area emerged in 1920 when the concept of public health was presented by C.A.E. Winslow, who emphasized that public health is the science and art of preventing disease, as well as prolonging life and promoting physical health through community effort, environmental hygiene, and infection control. Other measures include teaching the principles of personal hygiene and organization of medical and nursing services aimed at preventing diseases. Early diagnosis and development of social mechanisms to ensure that each individual and community has the living conditions to maintain health is also vitally important (Latalski, 1999). Public health is a science that focuses specifically on disease prevention and early detection. Furthermore, disease prevention is comprised mainly of personal hygiene, infection control, and organization of medical services. Another primary objective is to maintain health through adequate living conditions in the community.

This paper will analyze the current legal regulations affecting selected legal challenges related to the COVID-19 pandemic using the formal-dogmatic method. It will highlight and analyze the current epidemic threats affecting public health. The main problems and challenges will be defined. The paper also will present suggested solutions for preventing the spread of infectious diseases. Attention will be drawn to the introduction, during the course of the COVID-19 pandemic, of a new type of qualified crime under Article 161 of the Criminal Code. The contribution will also discuss the most important - in the author's opinion - challenge connected with epidemic threats, i.e., the question of the efficiency of the system of obligatory preventive vaccinations. The method chosen to analyze statistics and reports of national and international services will effectively allow us to demonstrate the negative societal impacts that evading mandatory preventive vaccinations for the COVID-19 pandemic has, including various unforeseeable negative consequences.

Epidemic risks of the 21st century

Public health research has been conducted for years around the world. In the context of analysis of the risks associated with the spread of infectious diseases, however, such research is relatively rare. New light has been shed on these problems by the current COVID-19 pandemic, which has highlighted not only the gaps in healthcare systems of various countries but the hasty relegation of epidemic threats to the background. A review of 21 st century public health research reveals only moderate 
interest of the doctrine in issues related to counter-epidemic measures. Jajosky and Groseclose point to the very important issue of timely reporting by health agencies concerning anti-epidemic surveillance (Jajosky \& Groseclose, 2004).

Timeliness and speed in reporting on matters of public health are among the most important factors that affect the ability to maintain a high level of health security for the public. Advances in medical sciences, health sciences, and epidemiology have made it possible to determine seasonality of infectious diseases (more information on this topic can be found in: Fisman, 2007). One example is influenza, which poses an epidemic threat every year in every country, despite effective treatment and the existence of a flu vaccine. Due to the low mortality rate and the relative speed in recovery, the epidemic risk of this disease is not considered high.

The risk of an epidemic has been marginalized for several years. Effective and highly developed protective vaccinations offer a significant guarantee of protection against the spread of infectious diseases. This concerns, in particular, such diseases as tuberculosis, measles, zoonotic rabies, and polio. Advances in medical science allow for a refinement of vaccines and drugs against many diseases. However, one thing has been overlooked in the current pandemic. COVID-19 is a completely new phenomenon. It is an infectious disease that the world, and its scientists, have never encountered. The mistaken belief (by governments/politicians) that such threats do not exist, or that the risks are so small that they can largely be ignored, has resulted in a significant relaxation of legislatures' approach to the subject.

There has been an increase in the number of people infected with tuberculosis and measles in recent years. Relevant data are presented by the European Centre for Disease Prevention and Control (ECDC). The 2018 report $^{1}$ indicated that the incidence of tuberculosis is still present. Comparing the data for the years 2014 to 2018, the report shows that the trend is fortunately downward. In 2014 there were 61,820 cases, but the number decreased to 52,862 cases in 2018. Despite the existence of an effective vaccine for tuberculosis, the number of people infected remains concerning. In 2018, the highest number of infections were recorded in Romania (12,205), Poland $(5,478)$, and Germany $(5,429)$. Importantly, the numbers

\footnotetext{
${ }^{1}$ https://www.ecdc.europa.eu/en/publications-data/tuberculosis-annual-epidemiological-report-2018 (10 December 2020).
} 
in these countries have remained relatively constant for several years. The report also reveals that the highest infection rate in 2018 occurred in the age group 25-44. Overall, the rate in males was double that of females, although this imbalance was limited to age groups above 14 years.

The latest report, covering the period of 2018-2020, reveals a disturbing, continuing high incidence trend in France, Poland, Romania, and the United Kingdom. In 2018, 52,862 cases of tuberculosis were reported in EU/EEA countries. Five countries reported more than 5,000 cases (France, Germany, Poland, Romania, and the United Kingdom) accounting for 63 percent of all reported cases, with Romania alone accounting for 23.0 percent of all tuberculosis cases reported in 2018. ${ }^{2}$ In 2019, the trend for tuberculosis infections was similar. Detailed data for 2020 is being prepared. However, preliminary analyses suggest a similar overall trend in the incidence of tuberculosis. Tuberculosis is included in the WHO's elimination goal, which is to achieve incidence of no more than one case per million inhabitants by 2050. However, given the unsettling trend continuing in many countries, this goal, despite the distant target date, seems ambitious.

Measles is an old infectious disease for which there are effective protective vaccines. However, a breakthrough reveals how a known infectious disease can spread anew. In Poland, for example, 48 cases of measles were reported as recently as 2015. In 2016, there were 133 cases. The breakthrough year was 2019, with as many as 1,503 cases of measles identified. ${ }^{3}$ Measles in Poland is covered by a mandatory protective vaccination program. Reports indicate that in Poland the vaccination program provides coverage to at least 90 percent of the population. 4 An analysis of the latest data for the period from December 2019 to November 2020 for European countries indicates that a total of 2,207 measles cases were reported. The largest number of cases $(1,094)$ was recorded in Romania. Poland in that period had 38 cases. For the sake of comparison, 270 cases of measles were reported in France and 114 cases in Italy. ${ }^{5}$

\footnotetext{
2 https://www.ecdc.europa.eu/sites/default/files/documents/TB-Surveillance-report_24March2020.pdf, p. 31-32 (10 December 2020).

${ }^{3}$ https://www.gov.pl/web/gis/raport-stan-sanitarny-kraju-w-roku-2019 (10 December 2020)

${ }^{4}$ https://www.ecdc.europa.eu/en/publications-data/vaccination-coverage-second-dose-measles-containingvaccine-eueea-2018 (10 December 2020).

5 https://www.ecdc.europa.eu/en/publications-data/number-measles-cases-month-and-notification-rate-millionpopulation-country-26 (10 December 2020).
} 
The most recent data presented for the current time periods serve to underscore how the incidence of known infectious diseases continue to pose public health threats in European countries, despite the existence of effective vaccinations against these diseases. Compared to such additional threats as the current COVID-19 pandemic, the public health situation appears to be severely inadequate. While the preceding paragraphs discuss ongoing threats posed by both measles and tuberculosis, those two dreadful diseases are only two of a multitude of known, recurring infectious diseases that exist not only in Europe but throughout the world.

\section{The challenges to legal systems related to the need for rapid response to threats caused by biological pathogens. Definition of the primary objectives.}

Specifying the most important determinants of infectious diseases enables us to provide a precise and comprehensive definition of the challenges and goals facing the authorities of states to combat both existing and future threats:

1. infectious diseases are caused by biological pathogens;

2. communicable diseases spread regardless of national borders;

3. development of epidemic outbreaks of infectious diseases is unpredictable or very difficult to predict;

4. there are risks associated with discovering new infectious diseases, hitherto unknown; and

5. there are risks associated with mutations of known infectious diseases.

These factors necessitate that we design a general structure of anti-epidemic law not only for the protection against the occurrence of epidemic outbreaks but also to combat the spread of infectious diseases. Most importantly, the legal norms should be structured clearly and explicitly, preferably in a single act, at the level of a statute, supplemented by implementing acts. It also would be highly desirable to create a single public administration body responsible for protecting the public health. Decentralizing decision-making among a large number of authorities is detrimental in fighting these complicated, and fast-moving epidemics and serves only to thwart effective and rapid decision-making. Placing decision-making in a single body also makes it easier to send unified, clear messages to the public. 
The need for professionalism and specialized education in health and epidemiological agencies also plays a crucial role. Stringent requirements must also be instituted for both quarterly and annual reporting on the current situation in the country. The regulations introduced by the WHO are important. States Parties should carry out ongoing reporting. This is necessary in order for WHO structures to gather information on events through their surveillance activities and to assess their potential to cause the international spread of disease and possible disruption of international traffic. In the context of this issue, Article 6 of the International Health Regulations is critically important. It states that each State Party shall notify WHO, by the most effective means of communication available, through its IHR National Focal Point, and within 24 hours of assessing public health information, of all events that may pose a public health threat of international concern within its territory, as well as any health measures implemented in response to those events, is extremely important. Conversely, after notification, the State Party remains obliged to provide WHO with timely, accurate and sufficiently detailed public health information at its disposal on the notified event. The State Party also is required to identify all possible conditions affecting the spread of the disease and the health measures implemented. Moreover, each State Party must report the difficulties encountered and the support needed to respond to a potential public health emergency of international concern. ${ }^{6}$

Rapid responses to outbreaks are also essential. Infectious diseases do not respect national borders. They can transmit freely from person to person. Only rapid responses can help ensure success against an active epidemic threat.

Transnational cooperation is no less important. Only rules of conduct that are clear and simple to implement in cases of an epidemic or risk of an epidemic outbreak have a chance of success. Both intergovernmental cooperation, and cooperation within the WHO and the European Union, must remain a priority. The reporting and information activities of the European Centre for Disease Prevention and Control (ECDC) are also extremely important.

${ }^{6}$ International Health Regulations, 3 ${ }^{\text {rd }}$ Edition, World Health Organization, 2016. 
Finally, public law provisions must provide health and epidemiological agencies with appropriate powers. Having not only effective legal tools to combat infectious disease outbreaks but also the legitimate ability to restrict civil rights and freedoms (e.g., the right to participate in mass events and the freedom of movement) are essential elements to stopping the spread of infectious diseases or at least significantly minimizing their deleterious effects.

Concerning the objectives of such a health policy and the constituent elements that would give legal formulation to such policy(s), the following should be considered and ought to form the core of said policy(s):

1. achieving close intergovernmental and community cooperation on protecting populations against epidemic threats;

2. creating a transparent system of anti-epidemic laws;

3. elaboration of uniform rules of conduct in situations of epidemic threats;

4. providing health and epidemiological agencies with adequate powers to shape the situation of entities subject to quarantine restrictions;

5. developing and implementing a broad information campaign on infectious diseases, public health policy, and protective vaccinations.

\section{Criminalization of causing situations that pose a threat to human life and health resulting from exposure to an infectious disease - new challenges to criminal policies of states using the example of the amendment of Article 161 of the Polish Criminal Code of April 2020}

The formulation and enactment of appropriately shaped penal policies for crimes against life and health is also critical. The criminal law must fully protect and help guarantee the protection of human life and health, which of course are the most important legal values. Criminal-law protection against the spread of infectious diseases should be concrete. Provisions of criminal law in terms of types of crimes cannot be ineffective. The prosecution of crimes related to infectious diseases can be problematic. For example, the determination of the cause-and-effect relationship between a particular perpetrator and his actions and a victim is often extremely difficult. 
Legislative work on a number of criminal bills in Poland had intensified as the COVID-19 pandemic has continued. There have been amendments made to various provisions relating to penal or administrative repressions. The Polish legislature has introduced a new, modified type of the crime of intentional exposure to an infectious disease.

The crime of exposure to the HIV virus or other infectious disease is punishable under Article 161 of the Polish Criminal Code. ${ }^{7}$ This crime is characterized by intent so that the perpetrator must have actual knowledge that he or she is infected with a specific infectious disease, a sexually-transmitted disease, or HIV. It is reasonable to argue that mere awareness of the possibility of being infected is insufficient for there to be a violation of Article 161. Moreover, the offender, knowing that he or she is infected, must at least accept the possibility of infecting another person with the disease. The wording of Article 161 of the Criminal Code does not imply criminality for an unintentional exposure to HIV or other infectious diseases.

Until 2020, this provision was worded as follows: "anyone who, knowing that he or she is infected with HIV, directly exposes another person to such an infection, shall be punished by imprisonment for up to three years". Section two, on the other hand, provides for criminal liability of "anyone who exposes another person to a disease, knowing himself or herself to be afflicted with a sexually transmitted or contagious disease, or a serious incurable disease, or one that is a real threat to life, or one that directly exposes another person to contracting such a disease. A person who fulfills any of the prerequisites by his or her act shall be subject to a fine, a restriction of liberty, or imprisonment for up to one year".

The amendment, adopted in April 2020 due to the COVID-19 pandemic, resulted in a significant change in the characteristics of this offense. The punishment was also made more severe. The amendment provides that anyone who, knowing that he or she is infected with HIV, directly exposes another person to such infection shall be punished by imprisonment for a period of six months to eight years. On the other hand, anyone who, knowing that he or she is afflicted with a sexually transmitted or infectious disease, a serious incurable disease, or a disease that poses a real threat to life, directly exposes another person to infection with such a disease,

\footnotetext{
${ }^{7}$ Polish Penal Code (consolidated text: Journal of Laws of 2020, item 1444, as amended).
} 
shall be subject to the penalty of imprisonment for a period of three months to five years. Immensely importantly, a new variation of this offence was introduced. Under the new legislation, if the perpetrator exposes many persons to infection, he or she shall be punished by imprisonment for a period of one to ten years.

This new crime is set forth in Article 161(3) of the Polish Criminal Code. By "many people," it is assumed that this number is more than ten people. As the doctrine aptly points out, when assessing the characteristics of this type of crime, one should first of all pay attention to the nature of the infringed good and the size of the harm done or threatened. In this case, the object of protection is undoubtedly human health and, more broadly, epidemic safety. The harm this offense is meant to eliminate clearly exists if the scale of the threat concerns an unspecified number of persons. Such an assumption is crucial to the findings on the subjective side of the offense in question (Kubiak, 2020). Undoubtedly, Article 161(3) is the Polish legislature's response to the threat of the spread of infectious diseases, and in particular in present times, and with respect to the social situation, the spread of the virus that causes COVID-19.

A valid question is whether increasing the statutory penalty and introducing a new modified type of offense is legally necessary. Proving this offense seems relatively difficult. For example, as an initial matter, even identifying the alleged offender can itself pose challenges. Hypothetically, let us assume a typical situation where a knowingly infected person enters a store to shop, wearing a protective mask. Others in the store are unaware that this person is infected. Has this person directly exposed others to the infection? It appears not. This conclusion is supported by the fact it is forbidden to apply a broad interpretation or inference per analogiam (by analogy) in order to establish criminal liability. Hence, the new legislation should be evaluated with a high degree of skepticism.

In reality, assessing the effectiveness of legislation of this nature to protect the public health sector is extremely difficult. A problem causing considerable practical difficulty is the absence of reference for the threats of this nature that resulted from the offense. Furthermore, it would be exceedingly difficult in such a situation to ascertain specifically how many people were exposed to infection in this way. Put another way, placing ourselves in the shoes of the victim(s) of this crime (a fellow 
shopper) how would we know that while shopping at this particular store we were exposed, let alone by whom?

As a result, there are far-reaching difficulties in detecting the cause-and-effect relationship between the perpetrator, his or her intention, the fulfillment of the characteristics of the crime provided for in Article 161 of the Criminal Code, and the result in the form of exposure to infection with a specific infectious disease.

Reference to the police reports is helpful when attempting to assess the application of the provisions of Article 161 of the Criminal Code. Police statistics track activity under Article 161. These statistics reveal that every year over a dozen proceedings are initiated under this Article. The number of offenses identified annually, however, has remained constant from several to over ten. The fact that proceedings under this Article are undertaken is noteworthy. According to police statistics, on average more than half of the crimes reported are not proven. ${ }^{8}$ Both the small number of reported cases and the even smaller number of convictions is testament to this provision's insignificance. However, the upward trend in the initiation of proceedings gives a glimmer of hope that in the future proceedings under this Article may increase as will its utility in terms of fulfilling the legislator's intent in passing it into law. Additionally, in light of the 2020 amendment, it will be interesting to monitor the trend from the perspective of the new qualified type of proceeding.

\section{The importance of protective vaccinations in the fight against infectious diseases - a challenge for the state and the society}

Protective vaccinations are widely recognized as one of the most effective ways to preventively combat the spread of infectious diseases, thereby reducing the occurrence of certain infectious diseases. The literature indicates that protective vaccinations are one of the most important factors affecting public health (Pierik, 2018; Kraljić \& Kobal, 2018).

\footnotetext{
${ }^{8}$ https://statystyka.policja.pl/st/kodeks-karny/przestepstwa-przeciwko/63436,Narazenie-na-chorobe-wywolanawirusem-HIV-zakazna-lub-weneryczna-art-161.html (15 December 2020)
} 
Governments have a duty to protect the public, especially children, from epidemics. Policies regarding protective vaccinations against known infectious diseases should be implemented smoothly and continuously. Only by maintaining a high vaccination rate is it possible to maintain both an adequate level of public health and security.

The occurrences of infectious diseases can be dramatically reduced. Achieving this objective, however, requires solidarity between countries, united in their efforts to achieve the same health goals. The literature rightly points out that children deserve special protection. Their immune systems are just being formed, which makes them particularly vulnerable to many pathogens. This is especially the case since the human immune system is unable to create the antibodies necessary to combat all diseases (Bester, 2018; Pierik, 2018).

Despite the existence of effective protective vaccinations against many infectious diseases, such as measles, mumps, polio, and tuberculosis, unfortunately there has been a recent increase in the number of unvaccinated children. The rise of the antivaccine movement, hastened by the spread of false anecdotal information about vaccinations, and then coupled with the fear many have of adverse reactions to vaccines, are limiting the number of people securing protective vaccinations.

The phenomenon of people evading mandatory protective vaccinations is becoming increasingly apparent. In European countries and the USA, for example, the decline in the number of vaccinated people has caused many dangerous infectious diseases to flourish in recent years (Ricciardi, Boccia, \& Siliquini, 2018). Importantly, European countries that have experienced an increase in infectious diseases are returning to protective vaccinations (Navin \& Attwell, 2019). These countries also are strengthening existing legal sanctions for the refusal to take vaccinations (Navin \& Attwell, 2019a).

The introduction of compulsory protective vaccinations is necessary in view of the growing trends in the incidence of some known infectious diseases. For example, France has had eleven mandatory protective vaccinations since 2018, Italy has introduced ten mandatory protective vaccinations for children under 16 since 2017, and Slovenia has introduced nine (Walkinshaw, 2011). Studies conducted in the USA clearly show that the lack of vaccinations leads to an increased incidence of many diseases (Weithorn \& Rubinstein Reiss, 2018). 
This perspective is very important when considering the reasonableness of the continued existence of protective vaccinations and the laws that govern them. What is needed is a rational and concrete supranational health policy and correlated national policies. The experience related to the performance of protective vaccinations should shed light on the current challenges associated with broad introduction of vaccines against COVID-19.

A serious question is whether vaccinations against COVID-19 should be voluntary or compulsory. This, in turn, raises the question whether vaccinations for other, preexisting infectious diseases should be made compulsory in all countries in order to expedite the improvement of health security. In this regard, there are numerous challenges confronting the world's healthcare and legal systems. There is an important need for the World Health Organization, the European Union, and other countries/organizations to work harmoniously, by taking united positions, as opposed to working in disharmony, in order to effectively counter the spread of infectious diseases both now and in the future.

\section{Challenges to the system of compulsory protective vaccinations in Poland in connection with alarming trends of disease incidence in the region}

The current situation in Poland deserves special attention. Despite the wide catalogue of infectious diseases against which there is an obligation to vaccinate, the number of unvaccinated children increases every year. In recent years, there have been increased anti-vaccine movements in the country, and its proponents are aggressively advancing numerous initiatives to liberalize vaccination laws.

A few clarifying remarks should be made about the Polish system of laws concerning obligatory protective vaccinations. Obligatory vaccinations in Poland are regulated by the Act of 5 December 2008 on preventing and combating infections and infectious diseases in humans (Consolidated text: Journal of Laws of 2020, item 1845, as amended). The Act requires persons obliged to undergo vaccinations to submit to a pre-vaccination eligibility examination followed by the actual vaccination. The objective and subjective scope of this obligation is specified in the Regulation of the Minister of Health of 18 August 2011 on compulsory protective vaccinations (Journal of Laws no. 182, item 1086). 
Importantly, the penalties for evading mandatory vaccinations are set forth in the misdemeanor law. Administrative enforcement measures must first be taken and concluded before the sanction provided for in Article 115 of the Misdemeanor Code may be imposed. When, despite their application, the obliged person fails to submit to a mandatory protective vaccination, he or she is subject to a fine of up to PLN 1,500 (approximately USD 350) or a reprimand. Pursuant to Article 115(2) of the Code of Misdemeanors, a person who, while exercising custody over a juvenile or helpless person, despite application of administrative enforcement, fails to subject the person to the protective vaccination or examination specified in sec. 1, shall be subject to an analogous penalty. Therefore, in the case of obligatory vaccination of children and youth up to 18 years old, the persons required to ensure compliance with this obligation are the legal or factual guardians of the juveniles.

2018 was a watershed year in Poland respecting the social debate over mandatory vaccinations. A citizens' bill was submitted to the lower chamber of the Polish Parliament (Sejm), which provided for the abolition of mandatory protective vaccinations. The proponents of this proposed bill argued the legislation would not only protect the right to human dignity and self-determination but also the rights of parents to raise their children in accordance with their own beliefs. The bill therefore called for only voluntary vaccinations (Sejm Paper no. 2796). This bill was opposed by the medical and nursing communities and ultimately was rejected in the course of the legislative works of the Sejm.

What is also important from the point of view of social and legal discourse is the numerous expert reports and opinions commissioned by state authorities. For example, the Chancellery of the Senate of the Republic of Poland (Office of Analysis, Documentation, and Correspondence) published a study in March 2018 entitled: "Controversy over Mandatory Vaccinations." The concluding remarks highlighted the risks associated with the return of some infectious diseases and, consequently, an overall increase in the number of diseases, at a time when the downward trend in compliance with the obligation to vaccinate continues to deepen (Study of the Office of Analysis, Documentation, and Correspondence of the Chancellery of the Senate of the Republic of Poland entitled: "Controversy over Mandatory Vaccinations," no. OT-660). 
An analysis of the available statistical studies indicates an alarming upward trend in the percentage of unvaccinated persons. The latest study, published in 2019 by the Centre for Public Opinion Research, suggests a modest reversal of this negative trend. ${ }^{9}$ This study indicates that the respondents were less likely to support voluntary vaccination. The study also notes that the respondents expressed greater support for mandatory vaccination for the most dangerous infectious diseases. In 2019 alone, it is estimated that there were nearly 50,000 children and adolescents under the age of 19 that evaded mandatory vaccinations. By comparison, there were nearly 3,500 cases of evasion in 2010, 16,689 in 2015, and 40,342 in 2018. ${ }^{10}$ Clearly, the tendency to evade mandatory vaccination is increasing and still gaining momentum. ${ }^{11}$

The experience in Poland demonstrates the multiple challenges faced by the legal system regarding mandatory vaccinations. Although the number of unvaccinated persons is increasing, the legislature has stubbornly refused to take steps to pivot away from failed methods and toward the use of other, more effective, legal sanctions. Consequently, Poland continues to face a sharply upward trend in (especially young) persons refusing vaccines and a correlative increase in the incidence of various infectious diseases. As indicated earlier, measles and tuberculosis are prominent examples of this problem.

In the context of vaccinations against COVID-19, which presently are voluntary in Poland, there is a risk of low vaccination rates. In an analogous model of voluntary influenza vaccinations, only approximately two-three percent of the Polish population is vaccinated annually. This casts great doubt on the future success of the campaign of voluntary vaccination against COVID-19. In this case, too, strong consideration must be given to taking appropriate legal steps aimed at achieving higher vaccination rates. In Poland, as elsewhere, convincing the public about the efficacy and safety of vaccines can pose significant challenges. The simple fact is, however, that society will return to normalcy only after most of the world's population receives vaccines.

\footnotetext{
${ }^{9}$ Information from the Public Opinion Research Centre no. 9/2019: “Attitudes toward Protective Vaccinations of Children."

${ }^{10}$ https://szczepienia.pzh.gov.pl/faq/jaka-jest-liczba-uchylen-szczepien-obowiazkowych/ (accessed on 13 December 2020 ).

${ }^{11}$ https://szczepienia.pzh.gov.pl/faq/jaka-jest-liczba-uchylen-szczepien-obowiazkowych/ (accessed on 13 December 2020).
} 


\section{Conclusion}

Infectious diseases have been a threat to individuals, societies, and humanity since time immemorial. Continuous changes in incidence patterns are due to social and cultural changes as well as advances in medical science. Taken together, these factors present a continuing challenge for institutions that work in the field of broadly defined public health.

The risks associated with the spread of infectious diseases are problems that defy respect for both national and regional borders. The threats are everywhere and, in an age of globalization and easy population movement, are increasingly acute. The unfortunate, continued presence of biological pathogens that cause known infectious diseases is problematic and concerning. Despite the introduction of compulsory vaccination and programs aimed to combat these diseases, statistics show that the risks continue. This problem must not be marginalized in any way.

The development of medical science has contributed to the improved level of health and epidemiological security for the vast majority of societies and countries. Effective treatment and preventive measures, such as vaccinations, are potent tools in the medical arsenal to maintain a high level of public health.

The enormous progress that has been achieved in medical and technical sciences over the years has resulted in huge improvements in the agencies responsible for epidemiological safety. The use of modern technologies during health and epidemiological examinations, as well as the unification of inspection procedures carried out by specialized bodies, definitely increases the level of protection of epidemiological security.

We must not ignore the difficult epidemiological and sanitary situation that exists in many regions of the world, including developing countries in particular. These conditions, along with the rapidly vanishing wilderness, create the perfect conditions for not only new disease threats but also for constant mutagenic changes in viruses and bacteria. Any of these potential threats might one day become a reality and result in yet another pandemic. Events in the 21st century have highlighted the problems associated with highly infectious diseases, which, given their disregard and disrespect for national borders, penetrate more territories. A highly advanced level of 
international cooperation among bodies that specialize in combating health and epidemiological hazards is extremely important in the fight against these constant and ever-growing threats.

At least a partial remedy to these problems is a clear and transparent regulatory system, especially one having a supranational character. Similarly, we must not disregard national systems for countering outbreaks. These systems comprise integral, constituent elements that are critically important if we are to minimize the risk of spreading communicable diseases outside the national territory at an early stage.

The further rapid development of both medical and legal sciences on protective vaccination systems is also necessary. Ensuring high rates of vaccinations in the world population is one of the most important challenges for achieving a high level of health security for both the European and global populations. The current COVID-19 pandemic, which has taken a deadly toll on the world population, is testament to all of the hard work that remains to be done not only to curb this deadly virus but to help arrest further infectious diseases.

\section{Legal sources}

Act of 6 June 1997 Penal Code (consolidated text: Journal of Laws of 2020, item 1444, as amended). Act of 5 December 2008 on preventing and combating infections and infectious diseases in humans (consolidated text: Journal of Laws of 2020, item 1845, as amended).

Regulation of the Minister of Health of 18 August 2011 on compulsory protective vaccinations (Journal of Laws no. 182, item 1086).

\section{References}

Bester, J.C. (2018) Not a matter of parental choice but of social justice obligation: Children are owed measles vaccination, Bioethics, 32(9), pp. 611-619, doi: 10.1111/bioe.12511.

Fisman, D.N. (2007) Seasonality of Infectious Diseases, Annual Review of Public Health, 28, pp. 127-143, doi: 10.1146/annurev.publhealth.28.021406.144128.

Jajosky, R.A. \& Groseclose S L. (2004) Evaluation of reporting timeliness of public health surveillance systems for infectious diseases, BMC Public Health, 4(29), doi: 10.1 186/1471-2458-4-29.

Kraljić, S. \& Kobal, A. (2018) Verschärfung der Gesetzgebungsansätze zur Impfungen in ausgewählten Staaten, Zbornik PFZ, 68(3-4), pp. 431-464.

Kubiak, R. (2020) Odpowiedzialność karna za narażenie na zakażenie wirusem SARS-COV-2, Palestra, (6), pp. 113-125.

Latalski, M. (1999) Zdrowie Publiczne i Medycyna spotecz̧na (Lublin: Akademia Medyczna).

Navin, M.C. \& Attwell, K. (2019) Vaccine mandates, value pluralism, and policy diversity, Bioethics, 33(9), pp. 1042-1049, doi: 10.1111/bioe.12645. 
Navin, M.C. \& Attwell K. (2019a) Childhood Vaccination Mandates: Scope, Sanctions, Severity, Selectivity, and Salience, The Milbank Quarterly. A multidisciplinary Journal of Population, Health and Health Policy, 97(4), pp. 978-1014, doi: 10.1111/1468-0009.12417.

Pierik, R. (2018) Mandatory Vaccination: An Unqualified Defence, Journal of Applied Philosophy, 35(2), pp. 381-398, doi: 10.1111/japp.12215.

Ricciardi, W., Boccia, S. \& Siliquini, R. (2018) Moving towards compulsory vaccination: the Italian experience, The European Journal of Public Health, 28(1), pp. 2-3, doi: 10.1093/eurpub/ckx214.

Walkinshaw, E. (2011) Mandatory vaccinations: The international landscape, Canadian Medical Association Journal, 183(16), pp. 1167-1168, doi: 10.1503/cmaj.109-3993.

Weithorn, L. A. \& Rubinstein Reiss, D. (2018) Legal approaches to promoting parental compliance with childhood immunization recommendations, Human Vaccines \& Immunotherapeeutics, 14(7), pp. 1610-1617, doi: 10.1080/21645515.2018.1423929. 